\title{
EDP Serviço Universal's energy market performance
}

\author{
A. Taborda ${ }^{1}$ and P. Andrade ${ }^{1}$ \\ ${ }^{1}$ Direção Compra de Energia \\ EDP Serviço Universal, SA \\ Av. Urbano Duarte, 100 - 3030-215 Coimbra (Portugal) \\ Phone number: +351 239002 000, e-mail: ana.taborda@edp.pt, patricia.andrade@edp.pt
}

\begin{abstract}
One of the EDP Serviço Universal's core activities is the purchasing and selling of electricity and the company must ensure the timely supply of energy to its customers. Furthermore the company must ensure the electricity purchase from producers with feed-in tariffs and the sale of all that energy through the spot and future markets.
\end{abstract}

The process involved in purchasing and selling electricity is quite complex and diversified from the legislative and regulatory point of view. This paper aims to present the functions of EDP Serviço Universal, as last resort supplier, and how the company operates in the electricity organised markets. This paper also focuses on the strategy followed for price optimisation and minimizing overcosts related to adjustments.

EDP Serviço Universal works to achieve and maintain efficient and timely performance through high quality service, preventing sanctions from the regulator while preserving the brand's equity to its stakeholders.

\section{Key words}

Purchasing and Selling of Electricity, Organised Energy Markets, Customers, Consumption.

\section{Introduction}

Electricity plays a huge part in people's live. Whether it is at home, school, workplace or daily routines, people heavily rely on the use of electricity. Like other commodities, electricity prices have a big impact not only in households, by affecting its available disposable incomes, but also in companies, impacting its competitive advantage in an open and global economy.

During the 1990s, with the aim of achieving the benefits of the liberalisation of the energy sector, organised markets began to emerge all over Europe promoting better quality services with lower prices to households and companies as well. A joint initiative by the Portuguese and Spanish governments resulted in the creation of the Iberian Energy Market (MIBEL) in July 2007. This major milestone opened up a market for the purchasing and selling of electricity between the two neighbour countries in a regime with free competition, equality and transparency.

\section{EDP Serviço Universal}

EDP Serviço Universal (EDP SU) is an EDP group subsidiary that buys and sells electricity as the last resort supplier. Last resort suppliers are licensed entities that must supply electricity to customers at the regulated tariff. It is also within EDP Serviço Universal's scope the purchasing of electricity in the organised markets in the right quantity to satisfy its customers and the role of the single buyer of the special regime production. In order to promote greater efficiency and transparency in the purchasing and selling of electricity the last resort supplier's activity has been split into:

- Purchasing and selling of electricity for consumption by its customers. As a last resort supplier, it has to purchase all required electricity to satisfy the consumption needs of its customers in organised markets, spot or future, through bilateral contracts with producers, suppliers or other licensed entities.

- Purchasing and selling of electricity from special regime producers, under feed-in tariffs, and sale of all this energy in the Iberian market, at market prices.

The following figure shows the electricity purchased by EDP Serviço Universal over the last five years (20122016). The quantity purchased has been decreasing over time, reflecting the switch of clients to other competitors in the liberalised market. A small but constant increase over time of electricity purchased to special regime producers can also be seen. It is important to mention that from the total electricity purchased by EDP Serviço Universal in 2016, 6 TWh have been acquired to satisfy the consumption of its clients' portfolio, while the remaining $22 \mathrm{TWh}$ have been purchased from producers with feed-in tariffs and consequently sold in organised markets. 


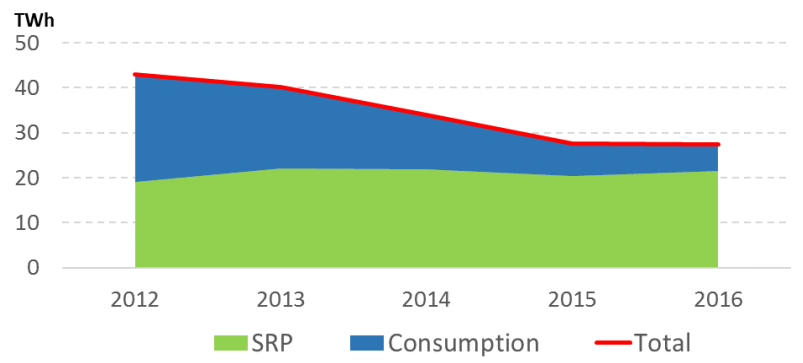

Fig. 1. Electricity purchased by EDP SU Source: EDP SU

\section{Organised Energy Markets}

The management of MIBEL's organised energy markets is split between two locations. One in Spain (OMIE - Iberian Energy Market Operator) that manages the daily and intraday markets and the other one is in Portugal (OMIP Iberian Energy Market Operator) that manages derivatives exchange market.

MIBEL's daily market is where electricity transactions take place for next day delivery. The price is set for each of the 24 hours of the day, 365 days per year. In this market, electricity prices are set daily at $12 \mathrm{pm}$ for the next 24 hours. The price and volume of energy in a specific hour are determined by the point at which the supply and demand curves meet. Thus, it ensures that all buyers pay the same price and all sellers receive this same price single marginal price model.

MIBEL's intraday market is a complementary platform of the daily market. After the daily market, agents may once again buy and sell electricity on the intraday market, in different trading sessions some hours earlier than real time. There are six trading sessions operating like those described for the daily market where the volume of energy and each hourly price are determined by the point where supply and demand meet. Similarly to the daily market, the intraday market runs every day of the year. This market enables all the agents to adjust their position easily and under the same conditions as any other operator within the same day as the physical delivery, getting similar prices to those of the daily market. This makes the intraday market very competitive and with high liquidity. It also allows buying and selling agents to readjust their commitment (for purchasing and selling, respectively) up to four hours ahead of real time.

The following figure shows the daily and intraday market purchases made by EDP Serviço Universal over the last 5 years. The sharp decrease in daily market purchases is due to the switching of clients to the liberalised electricity market.

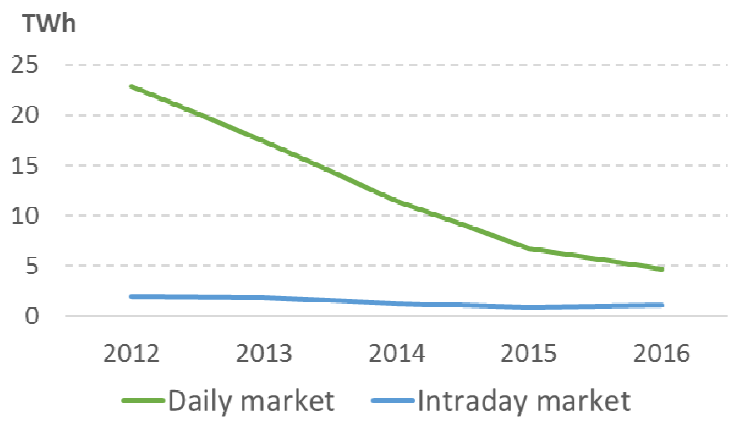

Fig. 2. Electricity purchased in OMIE by EDP SU Source: EDP SU

As buying and selling agents may trade in that market regardless of being in Spain or in Portugal, it is necessary to determine the commercially available interconnection capacity between these two countries and if it allows the flow of the electricity traded by the agents. So, if at a certain time of the day the capacity of the interconnection is sufficient, the price of electricity for that hour will be the same for Spain and Portugal. If, on the other hand, the interconnection is fully occupied at that time, the price of electricity for that hour will be different between the two countries. The mechanism described for setting the price of electricity in the daily market in Spain and Portugal is referred to as market splitting.

In the first year of the Iberian energy market the price of electricity was the same in Spain and Portugal only 20\% of the time. Gradual improvements in the interconnection between Portugal and Spain resulted in the price of electricity being the same over $90 \%$ of the time. This evolution can be seen in figures 3 and 4:

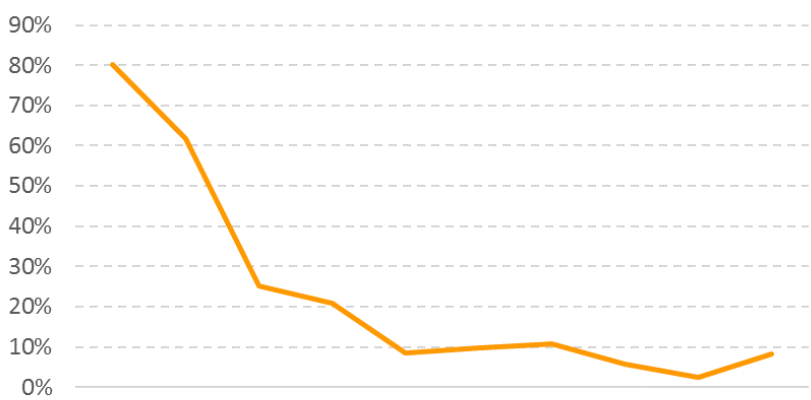

2007200820092010201120122013201420152016

Fig. 3. Market Splitting Portugal-Spain Source: EDP SU

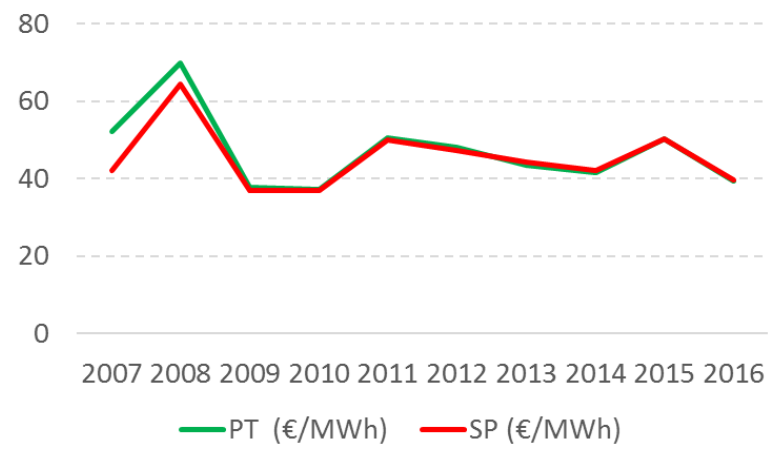

Fig. 4. Electricity prices between Portugal and Spain Source: OMIE 
Nowadays EDP Serviço Universal purchases all electricity required for its customers' consumption in the daily and intraday markets and the company also purchases all electricity produced by producers with feed-in tariffs, micro-producers, mini-producers, small production units and for self-consumption production units. The energy acquired from these producers is sold in the Iberian energy market.

The next figure shows how OMIE and OMIP's sales evolved over the last 5 years (2012-2016). In 2016, 27\% of electricity traded was sold in the derivatives exchange market.

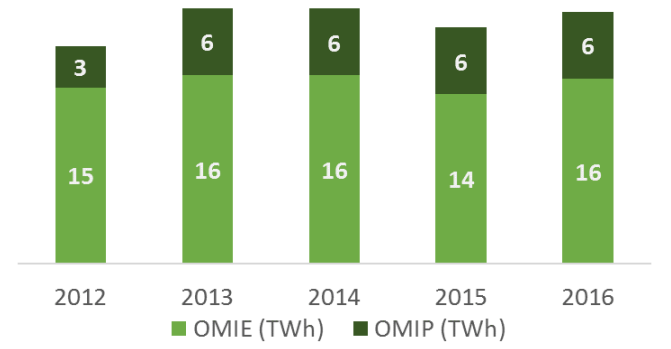

Fig. 5. Energy sales in Iberian Energy market by EDP SU Source: EDP SU

The derivatives exchange market offers risk management instruments under the form of derivatives. These instruments refer to purchase and sell contracts with a specified maturity (ranging from daily to yearly) that are available under specific terms and conditions. In this market the prices and volumes are agreed but can only be actioned at a predetermined date in the future. The energy sold by EDP Serviço Universal as futures contracts is delivered daily during the agreed period and taken into consideration in OMIE's daily billing.

The auctions of energy from producers with feed-in tariffs represent a valuable contribution to the market such as for the integration of renewable energy sources into the electrical system. Moreover, it is an instrument that can be used to cover commercial risks, helping to reduce exposure to daily market price volatility as well. As part of the participation in the derivatives exchange market, there is a clearance of results process which consists in the daily compensation of gains and losses resulting from the difference between prices agreed in the derivatives exchange market (OMIP) compared to the ones in the spot market (OMIE). This daily data is controlled on a daily basis and accounted for a specific methodology.

The results of the last 5 years show a positive cumulative figure in favour of EDP Serviço Universal, as it can be seen in the following figure:

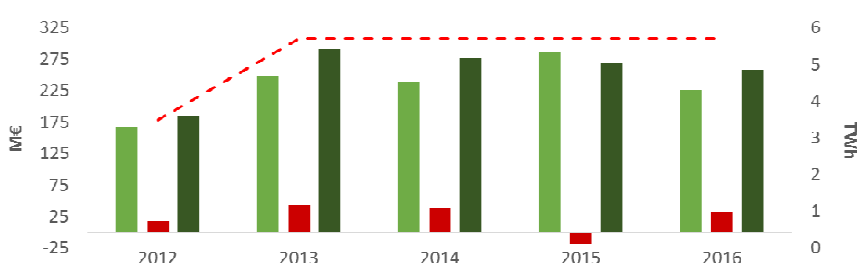

Valuation OMIE (M€) Results (M€) Valuation OMIP (M€) - - Energy (TWh)

Fig. 6. Results of energy selling in OMIP Source: EDP SU

\section{Customer consumption energy forecast}

The operation of EDP Serviço Universal is regulated with the objective of price optimisation in the purchasing and selling of electricity and the decrease of any deviation overcosts. To ensure this purpose, the company has an active participation in OMIE's intraday market so that it can adjust energy traded in the daily market and avoid overcosts with deviations.

On a daily basis EDP Serviço Universal forecasts customers' expected hourly demand as well as the supply from producers with feed-in tariffs, in order to manage purchase and sell orders of electricity. Since December 2009, the forecast is based on the "PECUR - Previsão de Energia do CUR" software that collects and stores all data from metering systems that later on is used to estimate consumption and production.

To trade the energy in the market, our activity is split up in two units:

- Purchasing Unit (EDPUC2), where we estimate the required energy purchase to meet demand from customers;

- Selling Unit (EDPSVD1), where we estimate the energy sale from producers with feed-in tariffs.

The customers' consumption forecast is created using a time series model which uses as inputs the historical data consumption of telemetered customers up to the previous day and the historical data consumption of nontelemetered profiled customers. This model allows EDP Serviço Universal to use other explaining variables such as customers switches, temperature forecasts' in specified areas that represents national consumption, weekend consumption, consumption of common holidays in Portugal and Spain and national consumption forecast.

The following figure demonstrates how overall customer consumption has decreased in the last five years. This continuous consumption decrease is justified by the customers switching to the liberalised market.

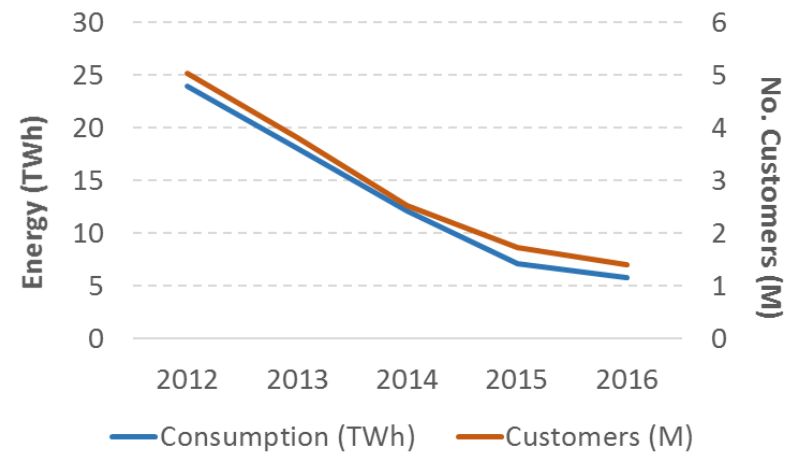

Fig. 7. EDP SU consumption and customers' evolution Source: EDP SU 


\section{Forecast errors}

Deviations result from the difference between the real value $\left(E_{t}\right)$ and the forecast value $\left(\hat{E}_{t}\right)$ of consumption and production. To analyse these deviations, the $\mathrm{MAPE}^{(1)}$ indicator (Mean Absolute Percentage Error) is used, corresponding to the average of absolute percentage errors for every hour, according to the real energy value.

$$
\text { MAPE }=\frac{1}{n} \sum_{t=1}^{n}\left|\frac{E_{t}-\hat{E}_{t}}{E_{t}}\right|, \mathrm{n}=\text { total hours }
$$

EDP Serviço Universal has a significant percentage of low voltage non-telemetered customers, making estimation exercise more difficult due to major sensitivities to variations in temperature. In December 2016, about 96\% of the customers' consumption was non-telemetered, mainly domestic customers.

However, the consumption MAPE indicator values are acceptable, even when compared to other suppliers.

As it can be seen from the following figure, the MAPE indicator ranged between $3,7 \%$ and $4,5 \%$ in the last five years:

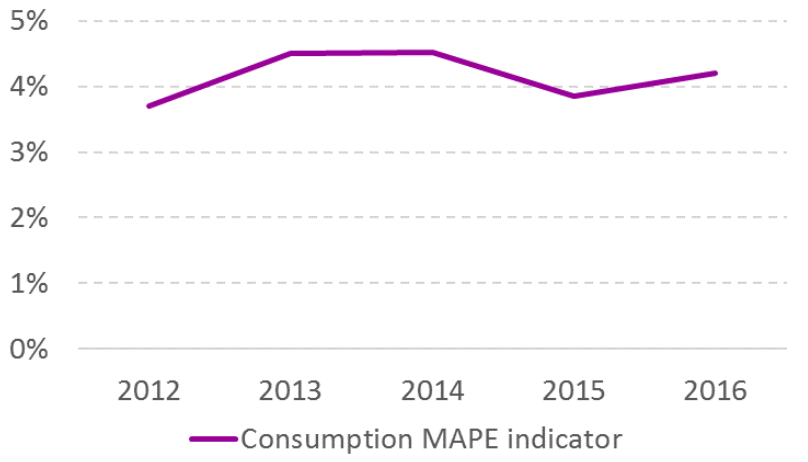

Fig. 8. EDP SU MAPE indicator evolution Source: EDP SU

\section{IT Systems}

The significant production and billing volumes, generated either from producers with feed-in tariffs or from the market trading, require a high degree of accuracy and transparency from the information systems. These systems need to be robust, reliable and auditable to provide real time quality reporting. For this purpose, two information systems were created, GPCE (Gestão de Produtores e de Compra de Energia) and PECUR (Previsão de Energia do CUR), to interface with transversal areas required for the purchasing/selling of electricity and creating EDP Serviço Universal's information management.

The GPCE application is used to record and check the information of transactions in the organised energy markets such as to manage and control electricity auctions and associated results, and to analyse and calculate deviations. Fig. 9. Screenshot of GPCE's Information System entry page
Source: EDP SU

The PECUR aggregates data from other information systems required to forecast consumption and the energy produced through feed-in tariffs.

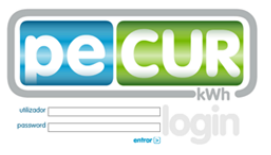

Fig. 10. Screenshot of PECUR's Information System login page Source: EDP SU

\section{Conclusion / challenges for the future}

EDP Serviço Universal is a regulated company which aims to keep performing a key role in the energy sector. It will also remain focused on accurately analysing of the available data, providing a timely quality response to prevent sanctions from the regulator and to promote interaction with different stakeholders. Furthermore, it will continuously improve its energy acquisition strategy through its forecasting models so that deviations can be reduced. However, the company will face new challenges, namely:

1. Volatility in the customer portfolio - return to the regulated market:

According to Law No. 105/2017, of August 30, customers can return to regulated market. It is expected that an oscillation will occur in the number of EDP Serviço Universal's clients and consequently in the total consumption. Similarly, customers' switching is a trend that is not expected to slow down. However, it is expected that the portfolio of clients continues being mainly composed of non-telemetered low voltage clients and consequently their consumption will increase complexity in calibrating forecasting models.

2. Permanent intraday market

EU 2015/1222 Regulation of July 24 establishes a guideline on capacity allocation and congestion management (CACM) and also defines the operation model of the European intraday market based on two fundamental points: 
- A permanent intraday market that uses a continuous process where collected orders are matched throughout day and capacity is allocated according the market participants location.

- Development of a methodology for capacity calculation, allocation and congestions management.

The Iberian daily and intraday market operator (OMIE) in conjunction with the Portuguese and Spanish National Electricity Systems operators (REN and REE respectively) suggest a hybrid operational model in which existent MIBEL's intraday market will be complemented with the Portugal-Spain interconnection in order to improve the coordination of the permanent intraday market. The ability to adjust the quantities to the following hour after the transaction will decrease the deviations' overcosts.

The European intraday continuous cross-zonal market is planned start operating in the first quarter of 2018.

\section{References}

[1] EDP Serviço Universal SA, Comercializador de Último Recurso, Compra de Energia,

http://www.edpsu.pt/pt/CUR/Pages/compraDeEnergia.aspx, september and october 2017

[2] OMIE, Mercado e Produto, Mercado da eletricidade, http://www.omie.es/pt/principal/mercados-e-produtos/conhecao-nosso-mercado, september 2017

[3] OMIP, Mercado, Modelo de Mercado, https://www.omip.pt/pt-pt/content/modelo-de-mercado, september 2017

[4] Entidade Reguladora dos Serviços Energéticos, http://www.erse.pt/PT/ELECTRICIDADE/Paginas/default.aspx, http://www.erse.pt/pt/supervisaodemercados/enquadramentoere gulamentacao/regulamentacaoespecifica/Paginas/default.aspx, september and october 2017

[5] Pedro Lourenço, Cristina Almeida, "Production under feedin tariffs in Portugal", International Conference on Renewable Energies and Power Quality (ICREPQ'16), Malaga, 2017

[6] Pedro Lourenço, Pedro Sá Furtado, "Micro-generation and Mini-generation - Sustainable production and efficient use of electrical energy in buildings", 40th IAHS World Congress on Housing, Funchal, 2014

[7] Antonio Brito, Luís Neves, "The feed-in tariffs structure of renewable and cogeneration energy in Portugal", $13^{\circ}$ Congresso Luso Espanhol de Engenharia Eletrotécnica, Valência, 2013 